\title{
Influence of steam singlet method on oil quality during deep fat frying on a modified fryer
}

\author{
El-Naggar, E.A. ${ }^{\mathrm{a}^{*}}$, Hassan, M.H.A. ${ }^{\mathrm{b}}$ \\ ${ }^{a}$ Food Science and Technology Department, Faculty of Agriculture, Al-Azhar University, Assuit, Egypt \\ ${ }^{b}$ Agricultural Engineering Department, Faculty of Agriculture, Al-Azhar University, Assuit, Egypt
}

\begin{abstract}
Nowadays, consumer trends towards healthier and low fat products have a significant impact on the deep fat frying industry. The objective of this study was to design a modified deep fat fryer (MDF) to have a smaller surface area relative to height, with made a steam blanketing over the fryer. Different levels of water injection flow rates have been used $(0.1,0.2$ and 0.3 $\mathrm{ml} / 20$ min. per 1 liter of tested oil), compared with conventional fryers (CDF). Frying was conducted at $170 \pm 10^{\circ} \mathrm{C}$ into sunflower oil using $\mathrm{CDF}(\mathrm{H} \sqrt{ } \mathrm{A}=0.24)$ and $\mathrm{MDF}(\mathrm{H} \sqrt{ } \mathrm{A}=0.8)$ in batch $8 \mathrm{~min} .16$ batches every day (eight hrs. /day)for up to $40 \mathrm{hrs}$ (Consecutive five days). The modification was intended to related oil deterioration. Water injection had a dual effect. In comparison with CDF, water injection increased the acidity (expressed as oleic acid) from $0.34 \%$ to $0.97 \%$, after $40 \mathrm{hrs}$ at $170 \pm 10^{\circ} \mathrm{C}$ of deep fat frying, and a contrarily, the protective role was observed in all the other quality indices. Significant reductions in TBA values (from 8.9 to $4.81 \mathrm{mg}$ malonaldehyde/liter of tested oil), $P$-anisidine values (from 35.6 to 12.9), TPC contents (from $34.5 \%$ to $18.64 \%$ ), conjugated diene ( $232 \mathrm{~nm}$ ) (from 8 to 5.59) and conjugated triene (268 nm) (from 1.9 to 1.33 ) were recorded in sunflower oil compared with CDF. These quality indices of sunflower oil developed dramatically in the first level of water injection flow rate. Consequently, the first level of water injection had the highest $(\mathrm{P} \geq 0.05)$ inhibitory effect compared with the other levels of water injection. Fatty acid composition of fried oil properties during deep frying CDF and MDF designs were determined. There were significant differences $(\mathrm{P} \geq 0.05)$ of fatty acids composition between the fried oil induces during using of CDF and MDF designs. Total unsaturated fatty acid at MDF design gave the highest values. Also, organoleptic evaluation of fried potato chips by CDF and MDF were evaluated by panelists. Fried potato chips during the first level of water injection flow rate had the highest ( $\mathrm{P} \geq 0.05)$ flavor (4), crisp (4.5), greasiness (4.6), and overall acceptability (4.8), compared with fried potato chips during other levels of water injection flow rates and with $\mathrm{CDF}$. Findings suggest that determination of the oil quality indices are good makers of sensory evaluation during deep fat frying. Results indicated the changes in moisture content, oil uptake and shrinkage percentages of potato chips at different levels of water injection compared the control samples. The negative correlation coefficient between oil uptake and moisture content was high $(\mathrm{r}=-0.915)$ and linear regression equation for prediction the oil uptake $\mathrm{y}=34.1064-$ 2.0291X. Also, results suggest that during deep fat frying by MDF design may reduce the thermal deterioration of sunflower oil. Water injection can be applied as a simple method to improve oil quality during deep fat frying.
\end{abstract}

Keywords: modified fryer, acid value, $P$-anisidine, thiobarbituric acid, polar compounds, ultra violet absorbance,moisture content, oil uptake, shrinkage, sensory evaluation, water injection.

*Corresponding author: El-Naggar, E. A., 


\section{Introduction}

Deep fat frying process is a fast and convenient technique widely used either in home or in restaurants. The popularity of frying is related to the unique sensory properties of fried food. The quality of oils and fats during the frying process has a major influence on quality of final product (Andrikopoulos et al., 2003; Suxuan and William, 2012). Deep fat frying involves simultaneous heat and mass transfers in food processing operation by immersing the food as a whole into the hot oil around or more than $180 \mathrm{C}$ temperature (Nayak et al., 2015). The process induces a variety of physicochemical changes in both the food and the frying medium (Ogunmoyela et al., 2016). In this process, a reverse transfer of water vapor from food to the oil and finally to the atmosphere occurs (Nayak et al., 2015).During the process, various chemical reactions such as hydrolysis, oxidation, isomerization and polymerization which resulted in the generation of free fatty acids, low molecular alcohol, aldehyde, ketone, acid, lacton and hydrocarbon, mono, diglycerides, cyclic and epoxy compounds, transacylglycerol monomer, dimer and oligomer. These reactions produce soluble, insoluble, volatile and nonvolatile matters (Nayak et al., 2015; Zhang et al., 2012). Unfortunately, the aforementioned beneficial effects of frying are accompanied by undesirable alteration of the frying medium. Thermal treatment of the frying oils results in oxidative and hydrolytic reactions; chemical and physical changes take place leading to the formation of undesirable secondary products (Sammak, 2013; Seppanen and Csallany, 2002). During intermittent deep fat frying, hydrolysis, oxidation and polymerization reaction cause a spectrum of physical and chemical changes, leading to the formation of decomposition products posing a direct impact damaging both the oil quality and the frying food nutritional value (Dana et al., 2003; Ogunmoyela et al., 2016). Several studies indicated that products generated through oil oxidation can mutagenic and carcinogenic (Saguy and Dana, 2003). Due to public health concerns, there is a strong demand to reduce the oil deterioration during fat frying. Thermally abused fats and oils are usually discarded because accumulation of oxidation products from fats and oils will not only reduce the sensory quality of fried foods but may also diminish their nutrition value (Martin and Ames, 2001; Saker, 2014; Sammak, 2013). Generally, $30 \%$ of used oils with batch process was discarded per week in a commercial frying operation. It is very important to minimize the waste oils generated during deep fat frying the point of the cost for disposal of the waste oil and effective utilization of oils. (Rimac-Brncic et al, 2004). Fujisaki et al. (2002) designed a deep fat fryer with low oxygen atmosphere $\left(2 \% \mathrm{O}_{2}\right)$ using $\mathrm{N}_{2}$ and then fried frozen chicken with vegetable oil. They reported that the increase in acid value, carbonyl values and the production of polymerized materials, and the decrease in tocopherols were related during frying. However, an $\mathrm{N}_{2}$ bomb is necessary for this system. Susinggih et al. (2000) designed a deep fat fryer under 
different vacuum levels the fried pineapple with vegetable oil. They found that the best frying temperature and vacuum pressure which were needed to produce pineapple crispy chips using simple vacuum fryer were $90^{\circ} \mathrm{C}$ and 700 $\mathrm{mm} \mathrm{Hg}$. The vacuum deep fat fryer was developed to reduce the thermal oxidation of fat and oils (Ahmad et al., 2013; Basuny et al., 2012; Diamante et al., 2015; Dueik et al., 2010; Fan et al., 2005; Garayo and Moreira, 2002; Negishi et al., 2003). The generation of volatile compounds in soybean oil was inhibited by water injection, after heating to $200{ }^{\circ} \mathrm{C}$ and storage for 26 weeks at 55 ${ }^{\circ} \mathrm{C}$ (Dana et al., 2003). Investigation reveals that several prototype deep fat fryers have been developed. These include: Open fryers which may either be single heat source or double heat sources, as well as pressure fryers designed to keep vapor inside the fryer while cooling (Ogunmoyela et al., 2016). The oil surfaces are designed to be large to enhance the production capacity in conventional fryers. However, the large oil surface increases the likelihood of thermal oxidation. When we measured the surface area (A) and height $(\mathrm{H})$ of the oil bath of the conventional fryers, the $\mathrm{H} / \sqrt{ } \mathrm{A}$ ratio was below 0.6 (Diamante $e t$ al., 2015; Negishi et al., 2003). Hence, we need to improve oil stability and prevent deterioration with new design that minimize the effect of oxygen, are required. We designed a modified deep fat fryer MDF to have a smaller surface area relative to height, which the $\mathrm{H} / \sqrt{ } \mathrm{A}$ of the oil bath was 0.8 , then made steam blanketing over the oil under three different levels of water injection flow rates, compared with conventional fryers (CDF). We deep-fried potato chips using the MDF and CDF, and then determined chemical characteristics and sensory evaluation during deep fat frying.

\section{Materials and methods}

\subsection{Materials}

\subsubsection{Sunflower oil}

The refined sunflower oil was obtained from Sohag oil and Soap Company, Sohag, Egypt.

\subsubsection{Potato tubers}

Potato tubers (Solamum tuberosum), were purchased from the local market of Assuit. They were cleaned, sorted, manually peeled using a sharp knife and then sliced to a thickness of 1.2-1.3 mm with a mechanical slicer, the slices were washed with tap water, immersed in $2 \%$ salt solution for $5 \mathrm{~min}$. and then washed again with tap water and let for $10 \mathrm{~min}$. to drain of excess water before they fried as reported by Abd-ElGhany (2006).

\subsubsection{Reagents}

All chemical and reagents used in the analytical methods (analytical grade) were produced by Sigma chemical Co. (St. Louis, Mo, U.S.A) and obtained from El-Gamhouria Trading Chemicals and Drugs Co., Egypt.

\subsubsection{Modified fryer (MDF)}

It was consisted of bath and steam blanket 
as shown in Fig. (1), the bath was fabricated from stainless steel. It was 140 $\mathrm{mm}$ diameter, $100 \mathrm{~mm}$ height and $2 \mathrm{~mm}$ thickness. A steam blanket was also fabricated from stainless steel and hinged with bath. It was like a cone and trapezoid cross section. The down base was 140 $\mathrm{mm}$; upper base was $300 \mathrm{~mm}$ and 250 $\mathrm{mm}$ height. The steam blanket had dual walls to through water tap from up to down as condensation operation of water vapor inhalation contained volatile compounds, which was collected by trap out MDF. The $\mathrm{H} / \sqrt{ } \mathrm{A}$ of the oil bath was 0.8 . The steam blanket partially removed in two cases; a- Put oil, water injection and potato chips, b- Take out the potato chips after frying. Water was injected by a nozzle to reduce the size of water droplets.

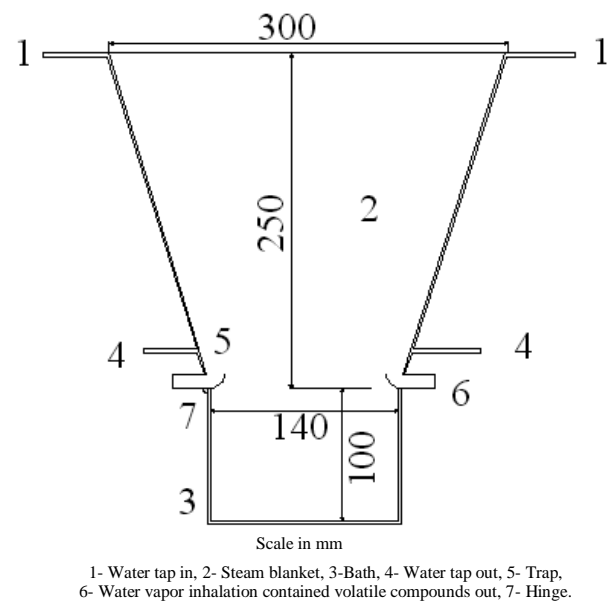

Figure (1): Modified deep fat fryer (MDF).

\subsubsection{Conventional fryer (CDF)}

The bath was fabricated from stainless steel. It was $280 \mathrm{~mm}$ diameter, $60 \mathrm{~mm}$ height and $2 \mathrm{~mm}$ thickness. The $\mathrm{H} / \sqrt{ } \mathrm{A}$ of the oil bath was 0.241 .

\subsection{Methods}

\subsubsection{Frying process}

One and half kgs, (For each treatment) of sunflower oil were used in the modified deep fryer MDF, under different level of water injection flow rates $(0,0.1,0.2$ and $0.3 \mathrm{ml} / 20 \mathrm{~min}$. per 1 liter) and three kgs.in conventional deep fryer $\mathrm{CDF}$, at 170 $\pm 10^{\circ} \mathrm{C}$ for $8 \mathrm{~min}$. with a constant product weight/oil volume ratio of $1: 6$, for up to 40 hours (Garayo and Moreira, 2002). Potato chips were used for frying in batches every eight hours ( $8 \mathrm{~min}$. /batch), after each frying the oil level was checked and replenished. At four an hours intervals during frying, about twenty milliliters of heated oil was withdrawn and kept in brown bottles in freezer at $18^{\circ} \mathrm{C}$ until used. All fried samples were allowed to cool to room temperature and sensory evaluated. All experiments were run in triplicate and the present results are the average of the obtained results.

\subsubsection{Analytical methods}

Acidity (expressed as oleic acid) was determined by the method of IUPAC (1987). $P$-anisidine value was determined by using the method of AOCS (1992). Thiobarbituric acid (TBA) value was determined by using the method of Keeney, (1971). The polar compounds content (TPC) was determined using chromatographic glass column method as described by Takeoka, et al., (1997). The ultra violet absorbance at $233 \mathrm{~nm}$ conjugated diene (CDs) and $268 \mathrm{~nm}$ 
conjugated triene (CTs) of oil samples were measured using (UV-visible spectrophotometer) as described by Danopouls and Ninni (1972).

\subsubsection{Potato chips properties}

\subsubsection{Moisture content}

Moisture content of potato chip was measured by drying the samples in vacuum oven at $60^{\circ} \mathrm{C}$ until reaching constant weight (AOAC, 2005).

\subsubsection{The oil content}

The oil content was extracted by chloroform and methanol based on the method proposed by (Pedreschi and Moyano, 2005).

\subsubsection{Shrinkage}

Degree of shrinkage in volume (Sv) was evaluated by:

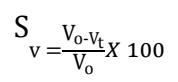

Where, Vo is the original volume of the sample $\left(\mathrm{m}^{3}\right)$, and $\mathrm{Vt}$ is the volume $\left(\mathrm{m}^{3}\right)$ of the sample at time $t$.

The volume of the sample (elliptical shaped) at any given time can be calculated by:

$$
V=(\pi D d / 4) L
$$

Where, D is the larger diameter of the sample $(\mathrm{m}), \mathrm{d}$ is the smaller diameter [m] of sample, and L is the sample's thickness (m).
Ten samples were taken to determine shrinkage for each frying condition at the equilibrium time (Pedreschi and Moyano, 2005).

\subsubsection{Organoleptic evaluation}

A tested panel of 10 numbers from the food Science and Technology Department, Faculty of Agriculture, AlAzhar University, Assiut, Egypt were asked to evaluate the effect of either conventional or modified deep fat frying on the fried potato for flavor, crisp, greasiness and overall acceptability using a scale from 1-5 points for each character (5) very good, (4) good, (3) fair, (2) poor and (1) very poor. This method was conducted according to the method of ElNaggar (2007).

\subsubsection{Data analysis}

Experimental data were analyzed by analysis of variance (ANOVA). The results were subjected to standard deviation and significance was tested by students ( $\mathrm{t}$ ) test. Differences between samples at the $5 \%(\mathrm{P} \geq 0.05)$ level were considered significant (Statistical Graphics Crop., 1998).

\section{Results and Discussion}

3.1 Effect of injecting water during deep fat frying on physical and chemical properties

During deep fat frying, a variety of reactions cause a spectrum of physical and chemical changes occur due to 
hydrolysis, oxidation and thermal decomposition. Fats and oils are oxidized to from hydroperoxides, the primary oxidation products and secondary oxidation products. These peroxides as extremely unstable and decompose via fission, to form as variety of chemical products such as alcohols, aldehydes, ketones, dimmers, trimmers, polymer and cyclic compounds (Basuny et al., 2012). Hence, we need to improve oil stability and prevent deterioration with new design that minimize the effect of oxygen, are required. We designed a modified deep fryer MDF (steam blanketing) in which the $\mathrm{H} \vee \mathrm{A}$ of the oil bath was 0.8 to minimize the generation of waste oil by reducing thermal oxidation deterioration of oils. The structure of MDF (higher $\mathrm{H} \sqrt{ } \mathrm{A}$ ) contributed to the smaller oil surface. Therefore, the new design reduces oxidation and thermal decomposition. The index of acidity is used as a chemical marker for monitoring the quality of frying operations and is often used for the assessment of frying oils suitability for human consumption. According to Miguel et al. (2014), the value of $2 \%$ is defined as the limit for oil rejection. Figure (2) shows the evaluation of acid value of fried oil properties during $\mathrm{CDF}$ and MDF. The differences in CDF and $\mathrm{MDF}$ at various water injection $(0,0.1$, 0.2 and $0.3 \mathrm{ml} / 20 \mathrm{~min}$. per 1 liter) were studied. Water injection had a dual effect on oil quality. In comparison with CDF, acid value of $0.25 \%$ for sunflower oil but increasing the water injection from
0.1 to $0.3 \mathrm{ml} / 20 \mathrm{~min}$. per 1 liter after 40 hrs at $170^{\circ} \mathrm{c}$ accelerated, as expected, the hydrolytic reactions giving rise to the formation of free fatty acids and increased acid values $(0.97 \%$ for first water injection level), (1.04\% for second level), (1.08\% for the third level) and $(0.3 \%$ for without water injection treatment) against $0.34 \%$ for CDF. Consequently, spraying of the frying oil with water remarkably increased the acid values throughout the whole experiment period. The relatively higher values for acid value than control samples could be attributed to rate of hydrolysis reactions. A water spray injection level of $0.3 \mathrm{ml}$ 120 min. per 1 liter over sunflower oil led to an acid value of $1.08 \%$ after $40 \mathrm{hrs}$ at $170^{\circ} \mathrm{C}$, while in oil kept under the same conditions and without water spray, the values was $0.3 \%$. The increase in acid values was due to a large water injection level. The results obtained were nearly similar with those obtained by Basuny $e t$ al. (2012), they reported that water and steam involve the breakage of triglycerides and produce monoglycerides, triglyceride, free fatty acids and glycerol. The role of water spray and oil quality during frying were evaluated. The water released during frying enhances heat transfer, may cause oil deterioration, and on the other hand also can prevent oxidation (Dana et al., 2003; Saguy and Dana, 2003). It is worthy to mention that a linear with a significantly correlation between frying time and acid value. The correlation coefficient of the third level of water injection was the 
lowest $(r=0.684)$ followed by the first conditions and no water spray injection and second levels of water injection $(r=\quad(r=0.958)$ against $(r=0.995)$ for $\mathrm{CDF}$ 0.758), while in oil kept under the same design.

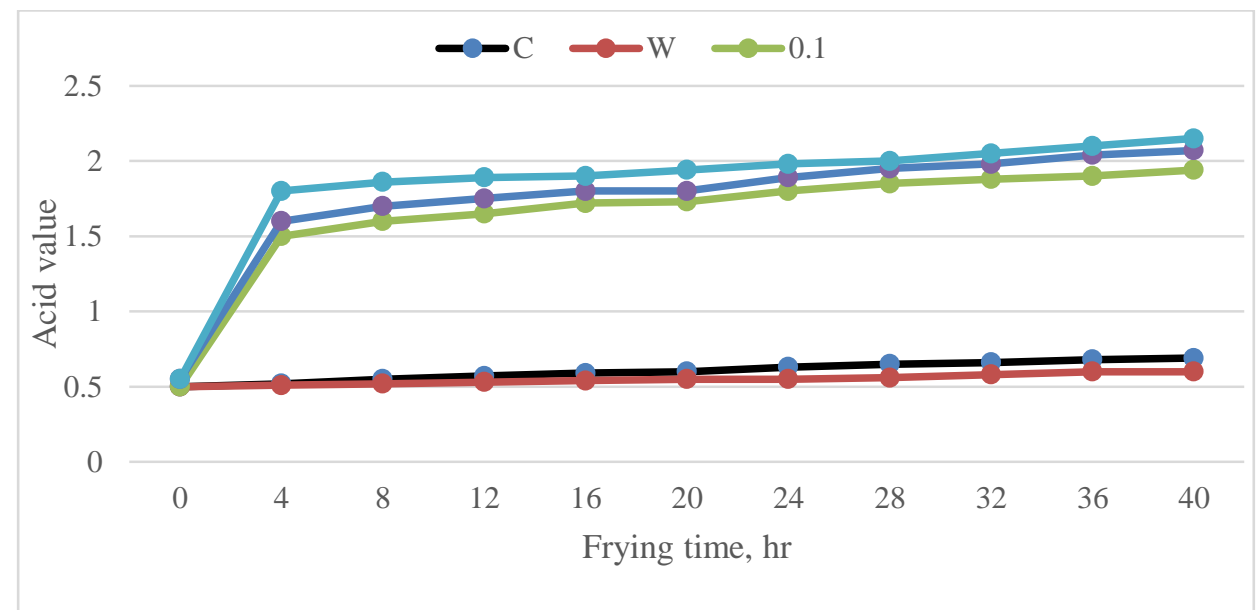

Figure (2): Effect of injecting water to sunflower oil during prolonged frying of potato chips at $170^{\circ} \mathrm{c}$ for $40 \mathrm{hrs}$ on acid value.

An opposite trend was observed in most parameters of deterioration. It could be observed that, the changes in $P$-anisidine values in sunflower oil during prolonged frying with $\mathrm{CDF}$ and MDF as shown in Figure (3). In comparison with the control, $P$-anisidine value of 5.3alkenal $/ \mathrm{kg}$ of oil, increasing the water injection level from 0.1 to $0.3 \mathrm{ml} / 20 \mathrm{~min}$. per 1 liter decreased $P$-anisidine values. The $P$ anisidine values were markedly lower due to water injection in sunflower oil. The $P$-anisidine values decreased from 23.45 to 12.9 alkenal $/ \mathrm{kg}$ of oil when the water injection level was $0.1 \mathrm{ml} / 20 \mathrm{~min}$. per 1 liter. The $P$-anisidine values for CDF oil was much higher 35.6alkenal $/ \mathrm{kg}$ of oil for sunflower oil. Nevertheless, had significantly $(\mathrm{P} \geq 0.05)$ changes were observed in $P$-anisidine value cited above between all levels of water injection throughout the $40 \mathrm{hrs}$ at $170^{\circ} \mathrm{C}$ of deep fat frying. Whereas, $P$-anisidine value decreased dramatically in the first level of water injection (12.9alkenal $/ \mathrm{kg}$ of oil) when the water level injection was decreased. Hence, the first level of water injection flow rate had the highest $(\mathrm{P} \geq 0.05)$ inhibitory effect on $P$-anisidine value in sunflower oil. Thereupon, water injection appreciably reduced $P$-anisidine value in sunflower oil. These reduction effects may be due to generating a steam (blanket) over the oil and preventing contact between air and oil. It can also play a role as a physical agent for steaming out, the volatile oxidative products from the oil and enhancing their evaporation (Rimac-Brncic et al., 2004; Shaker, 2014). This protective effect was 
observed previously during the frying of These results are coincident with those corn and canola oil saturated with water, reported by Saguy and Dana (2003) and $P$-anisidine value decreased from 77 and Dana et al. (2003). It is interesting to 97 to 39 and $67 \mathrm{mmol} / \mathrm{kg}$ respectively, when the water injection level increased from 0.1 to $1 \mathrm{ml} / \mathrm{min}$. after frying for 20 hrs (Dana et al., 2003). This protective role of water could be due to the large steam bubbles released from the oil. notice that a linear increasing with a significantly correlation between frying time (FT) and $P$-anisidine value. The positive correlation coefficient between frying time and $P$-anisidine value was very high $(\mathrm{r}=0.994)$.

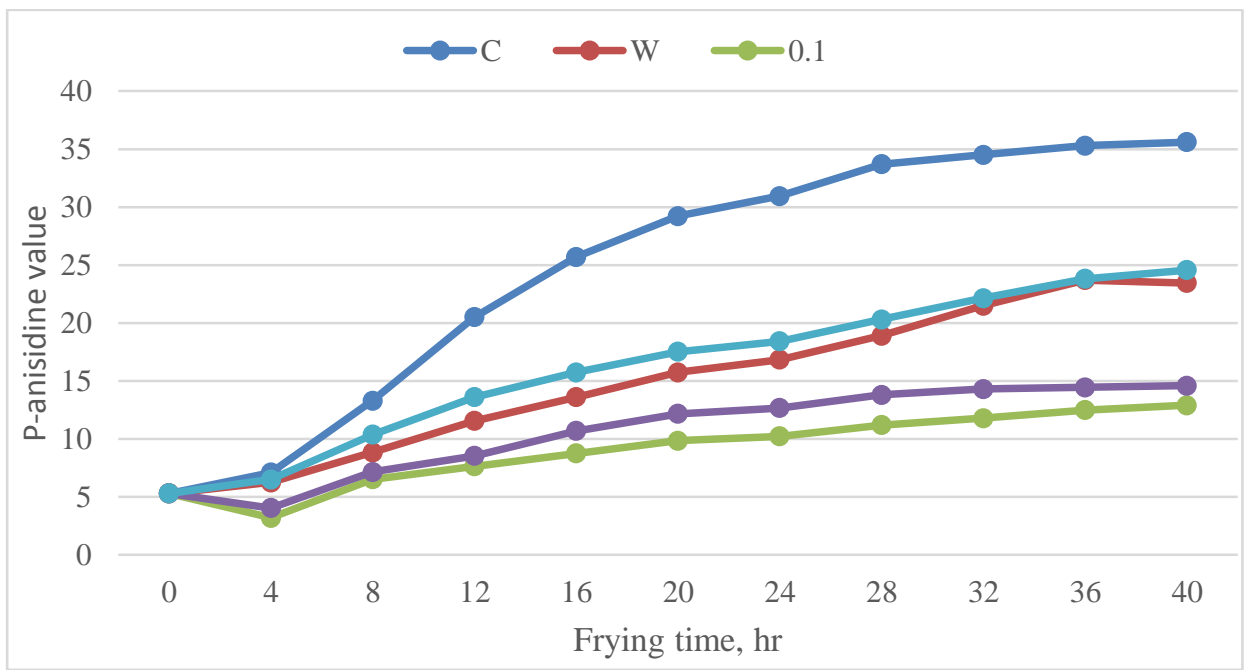

Figure (3): Effect of injecting water to sunflower oil during prolonged frying of potato chips at $170^{\circ} \mathrm{c}$ for $40 \mathrm{hrs}$ on $\mathrm{P}$-anisidine value.

Therefore, the linear regression equation for prediction the $P$-anisidine value of sunflower oil was:

$\mathrm{Y}_{(P \text {-anisidine value })}=5.225+0.492 \mathrm{X}(\mathrm{FT})$

Meanwhile, it could be observed a moderate correlation coefficient between $P$-anisidine value and acid value $(\mathrm{r}=$ 0.682 ). The measure of $P$-anisidine value is useful to correlate total Polar compounds (TPC), which is a laborious and expensive method. To examine the relationship between $P$-anisidine value (Rapid and simpler measurements of oxidation, we plotted the data obtained during frying experiments at $170^{\circ} \mathrm{C}$ for $40 \mathrm{hrs}, P$-anisidine value has a linear relationship with TPC. The respective correlation coefficient was $(r=0.979)$. The linear regression equation for prediction the TPC of oil was:

$\mathrm{Y}_{(\mathrm{TPC})}=-2.635+1.3858 \mathrm{X}_{\text {(P-anisidine value) }}$

Thereafter, the results suggest that determination of $P$-anisidine value is 
good marker of TPC in deep fat frying. With regards to the influence of TPC as a .basis for the assessment of the end point of frying we chose $25-27 \%$ TPC which is the regulatory limit in many European countries (Ahmad et al., 2013; Dueik et al., 2010). It is obvious from Figure (4) that, the water injection appreciably TPC concentration in MDF design in comparison with the CDF design, a water injection level of $0.1 \mathrm{ml} / 20 \mathrm{~min}$ per 1 liter over sunflower oil led to a TPC of $18.64 \%$ after $40 \mathrm{hrs}$ at $170^{\circ} \mathrm{C}$, while in oil kept under the same condition and no water spray, the TPC was $22.74 \%$. TPC value decreased $(\mathrm{p} \geq 0.05)$ dramatically in the first level of water injection level $(18.64 \%)$ as the water injection level decreased. Meanwhile, TPC content formed in sunflower oil significantly increased with prolonging frying period. Obtained data in Figure (4), also showed that, caused in general, a highly inhibition of TPC content at a variable rates depend upon frying time and water injection level.

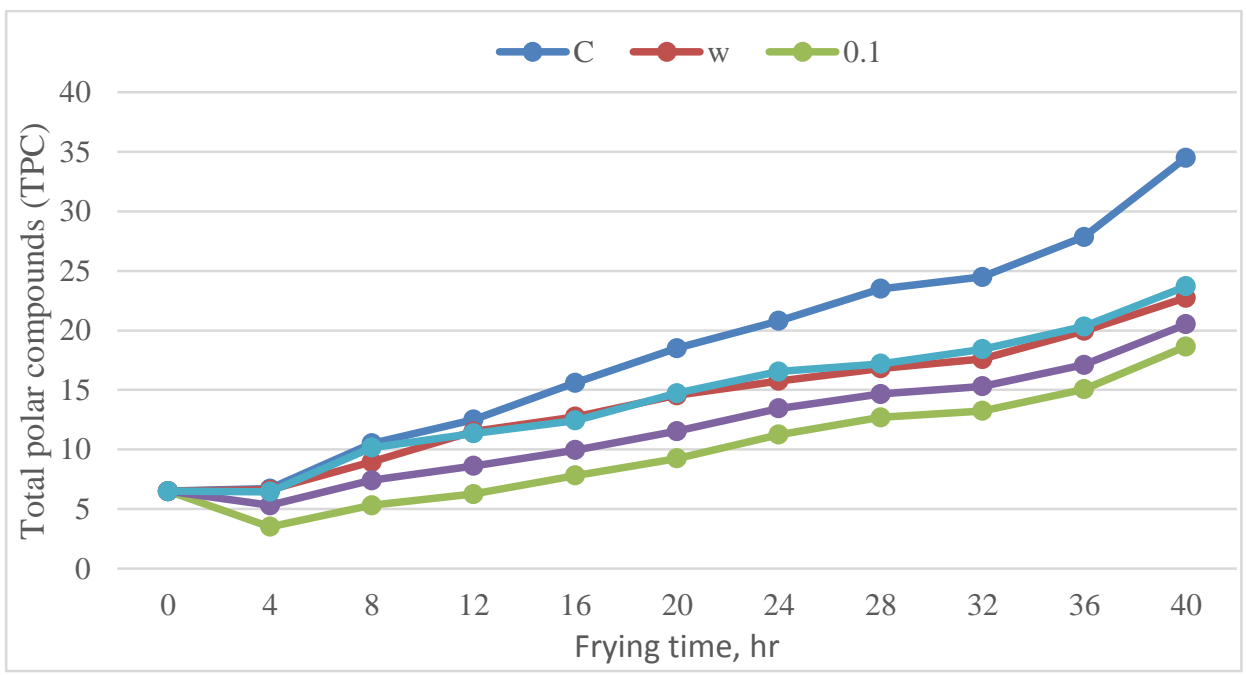

Figure (4): Effect of injecting water to sunflower oil during prolonged frying of potato chips at $170^{\circ} \mathrm{c}$ for $40 \mathrm{hrs}$ on total polar compounds (TPC).

These findings are in agreement with those Negishi et al. (2003) who reported that the thermal oxidation that produced TPC during deep fat frying at fryer, the ratio between height $(\mathrm{H})$ and surface area (A) was 0.93 could be retarded due to small surface of oil in contact with air. These results demonstrated that MDF was able to retard oxidation during deep fat frying .Hence, the inclusion of TPC value as a criterion for oil quality should be considered for monitoring changes in frying oils. It is worthy to mention that TPC content increased linearly with prolonged time during deep fat frying of oil at $170^{\circ} \mathrm{C}$. The correlation coefficient 
between the frying time and TPC was ( $\mathrm{r}$ $=0.955)$, and the linear regression equation for prediction TPC value was:

$\mathrm{Y}_{(\mathrm{TPC})}=3.27+0.3342 \mathrm{X}_{(\mathrm{FT})}$.

Many researchers revealing a decrease in total polar compounds with increasing water injection (Delgado et al., 2014), and as a consequence, the deterioration oil ratios is reduced by the water injection during intermittent deep fat frying processes. The above mentioned results are in harmony with those obtained by Suxuan and Willium (2012). With respect to thiobarbituric acid (TBA)value, which is considered a good chemical quality measure to identify the oxidation state of oil to measure the secondary oxidation .TBA test is a condensation reaction between the TBA and malonaldehyde (El-Naggar, 2007). As shown in Figure (5), water injection appreciably reduced TBA value in MDF method in comparison with CDF method. TBA value decreased from 8.9 to 4.81 when water injection level was $0.1 \mathrm{ml} /$ $20 \mathrm{mi}$ per 1 liter. A water spray level of $0.1 \mathrm{ml} / 20 \mathrm{~min}$ over sunflower oil led to a TBA value of 4.81 after $40 \mathrm{hrs}$ at $170^{\circ} \mathrm{C}$, while in oil kept under the same conditions and no water spray injection, the TBA value was 7. TBA value was considerably higher in CDF design, probably due to the higher surface area as compared with MDF design. Generally, first level of water injection level had significantly $(\mathrm{p} \geq 0.05)$ lower TBA value (4.81) compared with the second level of water injection (6.74) and / or third level of water injection. These findings are in harmony with those obtained by (Dana $e t$ al., 2003). Interestingly, TBA value increased linearly with a significantly correlation between frying time and TBA value. The positive correlation coefficient between TBA values and frying time was high $(\mathrm{r}=0.939)$. Thereafter, the linear regression equation for prediction the TBA values of oil was:

$\mathrm{Y}_{(\mathrm{TBA})}=2.4864+0.1191 \mathrm{X}_{(\mathrm{FT})}$

On the other side, the correlation coefficient between TBA value and TPC content was $(r=0.937)$. Consequently, the linear regression equation for prediction the TPC content of oil was:

$\mathrm{Y}_{(\mathrm{TPC})}=0.3740+2.935 \mathrm{X}_{(\mathrm{TBA})}$

Thus, consequently the results suggest that determination of TBA test is also good marker of TPC content in deep fat frying. The aforementioned findings of TBA test are in line with those obtained by Shaker (2014). Concerning the changes in ultra-violet absorption, the absorbance values reflect the presence of conjugated double bonds in the structure of oil molecule. These bonds are probably resulting of the formation of peroxides and other by products of oil oxidation. When unsaturated fatty acids are oxidized, to form hydroperoxides, the double bonds in the oils become conjugated, conjugated diene (CDs) may result from decomposition and 
absorption bond at about $232 \mathrm{~nm}$ which measures the degree of the primary oxidation products, while absorption bond at about $268 \mathrm{~nm}$ measures the secondary oxidation products formed from the initial compounds detected at $232 \mathrm{~nm}$. Both of conjugated diene (CDs) and conjugated triens (CTs) have been used as a good successful index for detecting the formation degree of conjugated fatty acids diens (CDs) and conjugated fatty acids trienes (CTs), respectively and they have been used to assess the changes during deep fat frying (Ahmad et al., 2013; El-Naggar, 2007; Tompkins and Perkins, 1999).

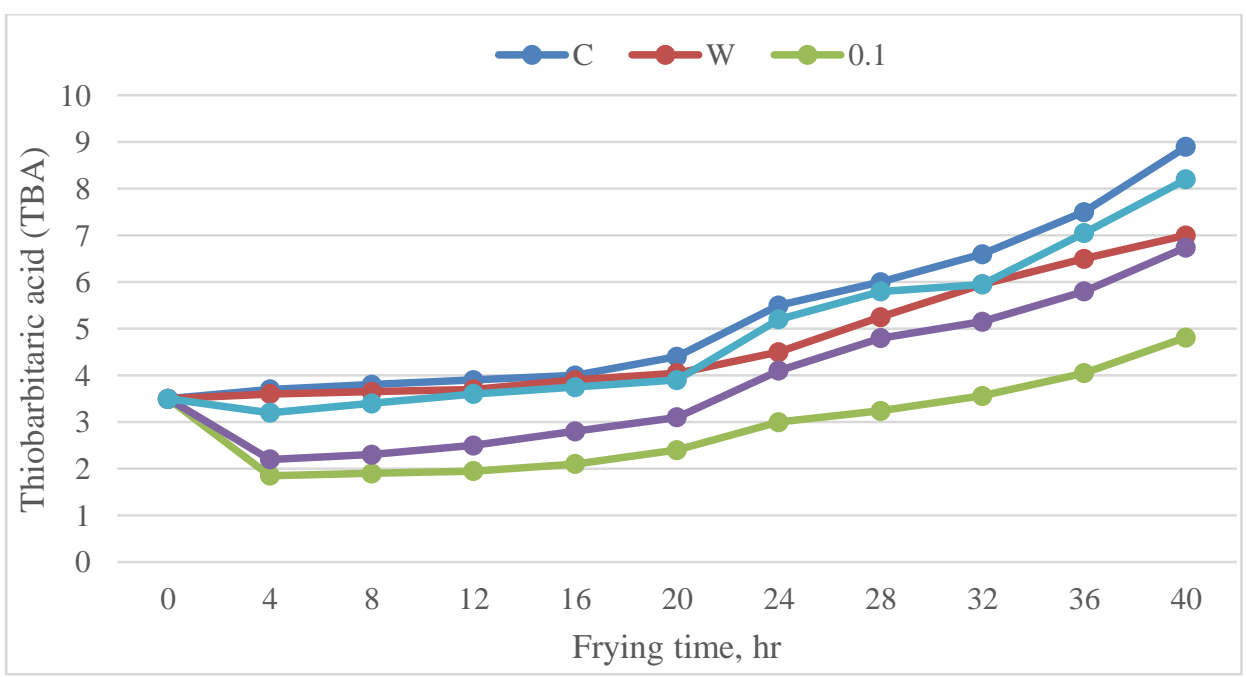

Figure (5): Effect of injecting water to sunflower oil during prolonged frying of potato chips at $170^{\circ} \mathrm{c}$ for $40 \mathrm{hrs}$ on thiobarbitaric acid (TBA).

Data given in Figure (6) indicated that the water injection reduced CDs concentrations. A water injection level of $0.1 \mathrm{ml} / 20 \mathrm{~min}$. reduced the CDs from 8 to 5.59 . Increasing the water injection to $0.3 \mathrm{ml} / 20 \mathrm{~min}$. was not effective in reducing the $\mathrm{CDs}$ in sunflower oil after $40 \mathrm{hrs}$ at $170^{\circ} \mathrm{C}$ of frying compared with the $0.1 \mathrm{ml} / 20 \mathrm{~min}$. water injection. These results are in agreement with a similar decrease in CDs due water dispersion in corn and canola oil after frying for $20 \mathrm{hrs}$ at $180^{\circ} \mathrm{C}$ (Dana et al., 2003). The same trend was observed in CTs. As shown in Figures (6) and (7) indicated that the CDF design samples contained a higher absorbance values at $232 \mathrm{~nm}(8)$ and at $268 \mathrm{~nm}$ (1.9) of oil than MDF design treatments. Meanwhile, absorbance values at 232 and $268 \mathrm{~nm}$ decreased $(\mathrm{P} \geq 0.05)$ dramatically in the first level of water injection (5.59) and (1.33) in oils respectively as water injection level decreased. 


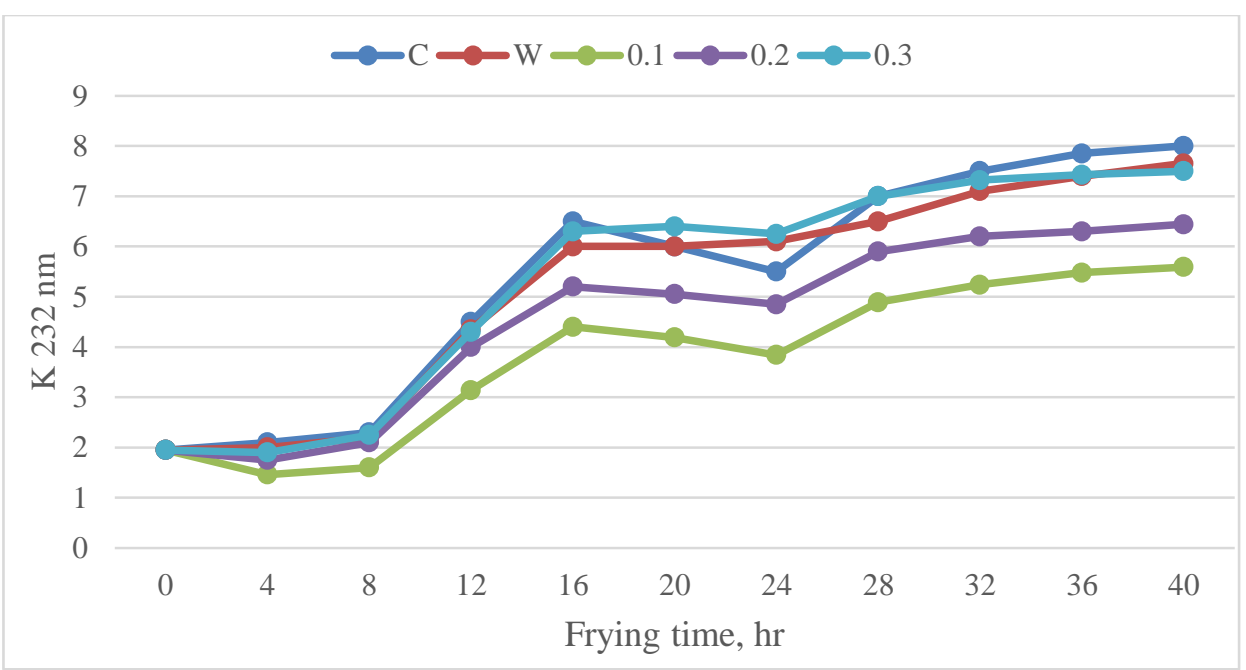

Figure (6): Effect of injecting water to sunflower oil during prolonged frying of potato chips at $170^{\circ} \mathrm{c}$ for $40 \mathrm{hrs}$ on $\mathrm{K} 232 \mathrm{~nm}$.

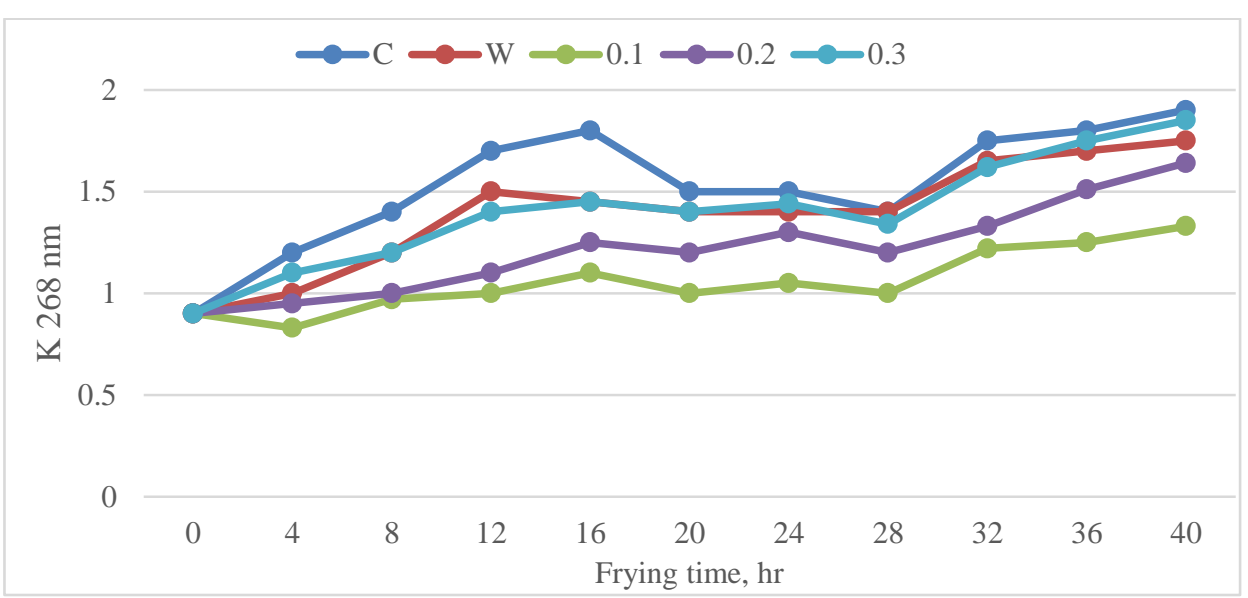

Figure (7): Effect of injecting water to sunflower oil during prolonged frying of potato chips at $170^{\circ} \mathrm{c}$ for $40 \mathrm{hrs}$ on $\mathrm{K} 268 \mathrm{~nm}$.

Hence, the first level of water injection had the highest $(\mathrm{P} \geq 0.05)$ inhibitory effect on absorbance values at 232 and $268 \mathrm{~nm}$ in oil compared to another water injection levels and CDF design samples. The reduction effect of the first level of water injection on absorbance values at 232 and $268 \mathrm{~nm}$ in oils may be owing to generating a steam (blanket) over the oil and preventing contact between oxygen and oil, caused small surface area of modified stainless steel vessel. Similar results are very close to those reported by (Dana et al., 2003; Delgado et al. 2014). It is interesting to notice that the positive correlation coefficient between CDs, CTs and TPC contents and both of CDs ( $\mathrm{r}=$ 0.937) and CTs $(r=0.908)$. The linear 
regression equation for prediction the TPC contents of oils were:

$\mathrm{Y}_{(\mathrm{TPC})}=0.961+2.4 \mathrm{X}_{(\mathrm{CDs})}$

$\mathrm{Y}_{(\mathrm{TPC})}=-12.5654+20.069 \mathrm{X}_{(\mathrm{CTs})}$

Thereafter, the data suggest that determination either CDs or CTs is also good marker of TPC content in deep fat frying.

\subsection{Potato chips properties}

Data given in Figures (8, 9 and 10) indicated the changes in moisture content, oil uptake and shrinkage percentages of potato chips of different levels of water injection and their comparative with control samples. It is worthy to mention that a linear decrease with a significantly correlation between moisture content and frying time (Ahmad et al., 2013). The correlation coefficient between moisture content and frying time was $(r=-0.59)$ for control samples. The linear regression equations for prediction the frying time (FT) were:

$\mathrm{Y}_{(\mathrm{FT})}=3.1309-0.0229 \mathrm{X}_{(\mathrm{MC})} \quad(\mathrm{r}=-0.590) \quad($ Control $)$ $\mathrm{Y}_{(\mathrm{FP})}=3.4318-0.02477 \mathrm{X}_{(\mathrm{MC})} \quad(\mathrm{r}=-0.647) \quad(\mathrm{WI}=0.1)$ $\mathrm{Y}_{(\mathrm{FP}}=3.3864-0.01459 \mathrm{X}_{(\mathrm{MC})} \quad(\mathrm{r}=-0.474) \quad(\mathrm{WI}=0.2)$ $\mathrm{Y}_{(\mathrm{FP}}=76.1792-17.606 \mathrm{X}_{(\mathrm{MC})} \quad(\mathrm{r}=-0.483) \quad(\mathrm{WI}=0.3)$

On the other side, the positive correlation coefficient between oil uptake percentage and frying time was very high $(r=0.905)$ for control samples. The linear regression equation for prediction the oil uptakes were:

\footnotetext{
$\mathrm{Y}_{(\mathrm{OU})}=29.8073+0.19436 \mathrm{X}_{(\mathrm{FT})} \quad(\mathrm{r}=0.905) \quad($ Control $)$

$\mathrm{Y}_{(\mathrm{OU})}=25.066+0.046023 \mathrm{X}_{(\mathrm{FT})} \quad(\mathrm{r}=0.968) \quad(\mathrm{WI}=0.1)$

$\mathrm{Y}_{(\mathrm{OU})}=25.057+0.0688 \mathrm{X}_{(\mathrm{FT})} \quad(\mathrm{r}=0.996) \quad(\mathrm{WI}=0.2)$

$\mathrm{Y}_{(\mathrm{OU})}=26.761+0.04352 \mathrm{X}_{(\mathrm{FT})} \quad(\mathrm{r}=0.714)(\mathrm{WI}=0.3)$
}

It is worth mentioning that, the weak correlation coefficient between shrinkage percentage and frying time was very low $(r=-0.174)$ for control samples. Similar results are very close to those reported by (Delgado et al., 2014).

$\mathrm{Y}_{(\mathrm{SH})}=14.7796-0.0006 \mathrm{X}_{(\mathrm{FT})}$

While, the correlation coefficient between shrinkage percentage and frying time was moderate $(r=-0.44)$ at water injection level (0.1) and linear regression equation for prediction the shrinkage percentage was:

$\mathrm{Y}_{(\mathrm{SH})}=10.2591-0.0007 \mathrm{X}_{(\mathrm{FT})}$

The correlation coefficient between shrinkage percentage and frying time was very low $(r=-0.139)$ at water injection level (0.2) and linear regression equation for prediction the shrinkage percentage was:

$\mathrm{Y}_{(\mathrm{SH})}=11.04-2.9544 \mathrm{X}_{(\mathrm{FT})}$

While, the correlation coefficient between shrinkage percentage and frying time was low $(\mathrm{r}=-0.187)$ at water injection level (0.3) and linear regression equation for prediction the shrinkage percentage was:

$\mathrm{Y}_{(\mathrm{SH})}=13.1341-0.0006 \mathrm{X}_{(\mathrm{FT})}$

The negative correlation coefficient between oil uptake (OU) and moisture content percentage (MC) was strong and linear regression equations for predication the oil uptake were:

\footnotetext{
$\mathrm{Y}_{(\mathrm{OU})}=37.3355-1.3623 \mathrm{X}_{(\mathrm{MC})}(\mathrm{r}=-0.246)($ control $)$

$\mathrm{Y}_{(\mathrm{OU})}=28.685-0.9191 \mathrm{X}_{(\mathrm{MC})}(\mathrm{r}=-0.74)(\mathrm{WI}=0.1)$

$\mathrm{Y}_{(\mathrm{OU})}=29.9642-1.1415 \mathrm{X}_{(\mathrm{MC})}(\mathrm{r}=-0.508)(\mathrm{WI}=0.2)$

$(\mathrm{OU})=34.1064-2.029 \mathrm{X}_{(\mathrm{MC})} \quad(\mathrm{r}=-0.915)(\mathrm{WI}=0.3)$
}

The positive correlation coefficient 
between shrinkage $(\mathrm{SH})$ and moisture The negative correlation coefficient content percentages (MC) were high and between oil uptake (OU) and shrinkage linear regression equations for $(\mathrm{SH})$ percentages was moderate and predication the oil uptake were: linear regression equations for predication the oil uptake were:

$\begin{array}{llllll}\mathrm{Y}_{(\mathrm{SH})}=12.66+0.7702 \mathrm{X}_{(\mathrm{MC})} & (\mathrm{r}=0.866) & (\text { Control }) & \mathrm{Y}_{(\mathrm{SH})}=13.807+0.02529 \mathrm{X}_{(\mathrm{OU})} & (\mathrm{r}=-0.157)(\mathrm{Control}) \\ \mathrm{Y}_{(\mathrm{SH})}=9.0794+0.3521 \mathrm{X}_{(\mathrm{MC})} & (\mathrm{r}=0.815) & (\mathrm{WI}=0.1) & \mathrm{Y}_{(\mathrm{SH})}=15.807-0.2123 \mathrm{X}_{(\mathrm{OU})} & (\mathrm{r}=-0.61)(\mathrm{WI}=0.1) \\ \mathrm{Y}_{(\mathrm{SH})}=9.01691+0.5855 \mathrm{X}_{(\mathrm{MC})} & (\mathrm{r}=0.85) & (\mathrm{WI}=0.2) & \mathrm{Y}_{(\mathrm{SH})}=12.3585-0.05212 \mathrm{X}_{(\mathrm{OU})} & (\mathrm{r}=-0.169)(\mathrm{WI}=0.2) \\ \mathrm{Y}_{(\mathrm{SH})}=9.376+1.1287 \mathrm{X}_{(\mathrm{MC})} & (\mathrm{r}=0.939) & (\mathrm{WI}=0.3) & \mathrm{Y}_{(\mathrm{SH})}=24.7943-0.4265 \mathrm{X}_{(\mathrm{OU})} & (\mathrm{r}=-0.779) & (\mathrm{WI}=0.3)\end{array}$

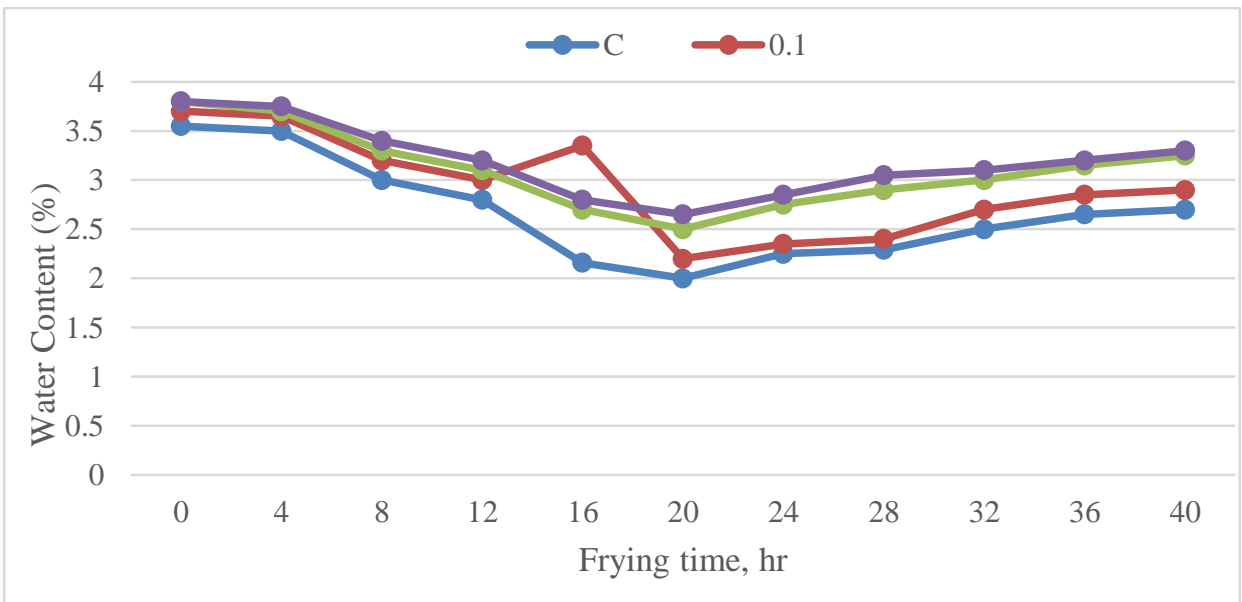

Figure (8): Effect of injecting water to sunflower oil during prolonged frying of potato chips at $170^{\circ} \mathrm{c}$ for $40 \mathrm{hrs}$ on water content $(\%)$.

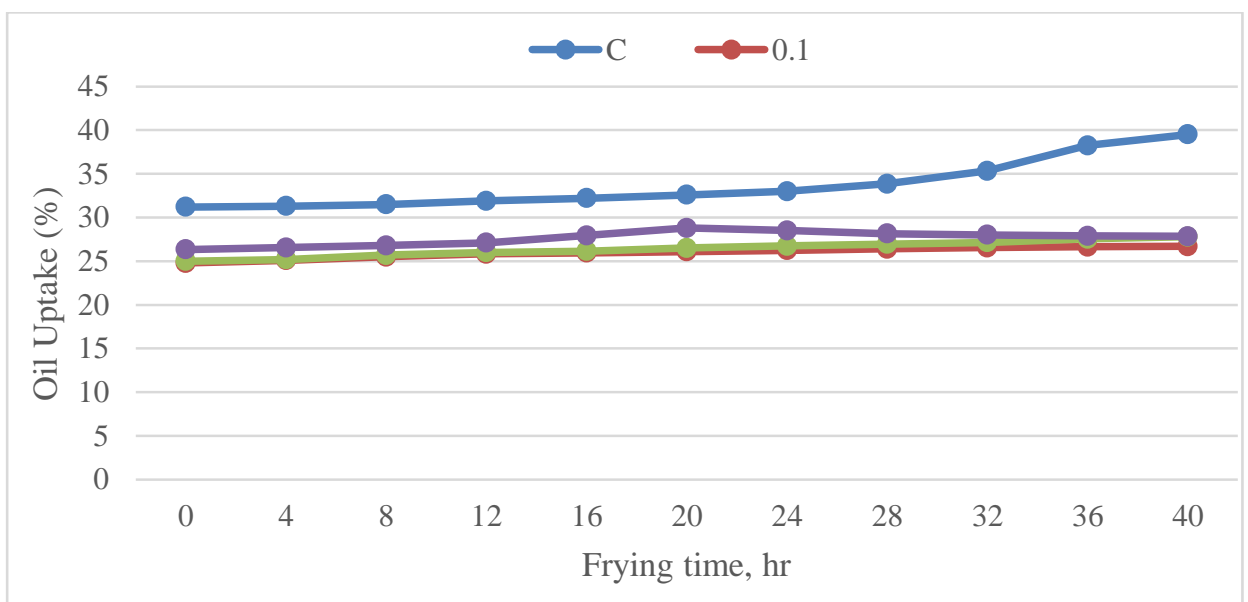

Figure (9): Effect of injecting water to sunflower oil during prolonged frying of potato chips at $170^{\circ} \mathrm{c}$ for $40 \mathrm{hrs}$ on oil uptake $(\%)$. 


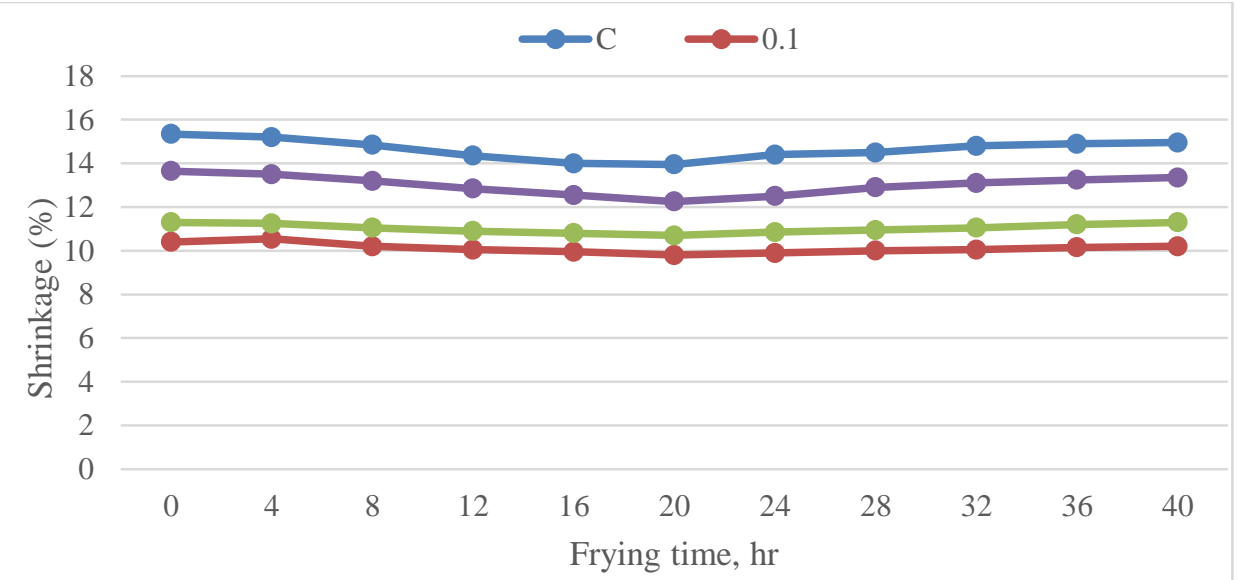

Figure (10): Effect of injecting water to sunflower oil during prolonged frying of potato chips at $170^{\circ} \mathrm{c}$ for $40 \mathrm{hrs}$ on shrinkage $(\%)$.

Thereafter, the influence of water injection level during deep fat frying process on moisture content, oil uptake and shrinkage percentages of potato chips, it could be noticed that water injection level of 0.1 showed considerably improved the further potato properties (Garayo and Moreira, 2002). Table (1) shows the evaluation of fatty acid composition of fried oil properties during $\mathrm{CDF}$ and MDF designs. There were significant differences $(\mathrm{P} \geq 0.05)$ between the fried oil properties during $\mathrm{CDF}$ and MDF design samples. Total unsaturated fatty acids at MDF gave the highest values.

Table (1): Effect of injecting water to sunflower seed oil after deep fat frying of Potato chips at $170^{\circ} \mathrm{C}$ for 40 hrs on fatty acid composition.

\begin{tabular}{lcccccc}
\hline Treatment & \multicolumn{2}{c}{ Control } & Without water & \multicolumn{3}{c}{ Water injection level after 40 hrs } \\
\cline { 1 - 1 } Fatty acid & Zero time & After $40 \mathrm{hrs}$ & injection & 0.1 & 0.2 & 0.3 \\
\hline $\mathrm{C}_{12: 0}$ & 0.36 & 0.65 & 0.60 & 0.54 & 0.55 & 0.57 \\
\hline $\mathrm{C}_{14: 0}$ & 0.50 & 0.15 & 0.20 & 0.33 & 0.30 & 0.25 \\
\hline $\mathrm{C}_{16: 0}$ & 17.04 & 30.00 & 28.00 & 24.70 & 24.69 & 26.01 \\
\hline $\mathrm{C}_{16: 1}$ & 0.30 & 0.35 & 0.34 & 0.30 & 0.33 & 0.34 \\
\hline $\mathrm{C}_{18: 0}$ & 3.80 & 3.50 & 3.38 & 3.29 & 3.32 & 3.20 \\
\hline $\mathrm{C}_{18: 1}$ & 23.10 & 33.00 & 30.03 & 25.72 & 27.88 & 29.00 \\
\hline $\mathrm{C}_{18: 2}$ & 55.50 & 32.20 & 37.30 & 45.12 & 42.80 & 40.50 \\
\hline $\mathrm{C}_{18: 3}$ & 0.1 & 0.15 & 0.14 & 0.12 & 0.13 & 0.13 \\
\hline Total sat. fatty acids & 20.98 & 34.30 & 32.18 & 28.86 & 28.86 & 30.03 \\
\hline Total un sat. fatty acids & 79.00 & 65.70 & 67.81 & 71.14 & 71.14 & 69.97 \\
\hline $\mathrm{C}_{18: 2 /} \mathrm{C}_{16: 0}$ & 3.25 & 1.07 & 1.33 & 1.82 & 1.73 & 1.55 \\
\hline
\end{tabular}

Meanwhile, total unsaturated fatty acid values increased in the first and second levels of water injection (71.14) against
(67.81) for MDF design without water injection and (65.7) for CDF design after $40 \mathrm{hrs}$ at $170^{\circ} \mathrm{C}$. Linoleic and palmitic 
acids are usually used as indicators of the extent of oil deterioration, because linoleic acid is more susceptible to oxidation, whereas, palmitic acid is more stable toward oxidation. Consequently, the ratio of $\mathrm{C} 18: 2 / \mathrm{C} 16: 0$ was used to indicate the degree of oxidation deterioration of frying oil. The ratio of C18:2/C16:0 was reduced during CDF and /or MDF while, first level of water injection contained the highest value of these ratio (1.82) followed by the second level of water injection (1.73) and then the third level of water injection (1.55) compared with (1.33) for MDF design without water injection and/or (1.07) for $\mathrm{CDF}$ after $40 \mathrm{hrs}$ at $170^{\circ} \mathrm{C}$.

\subsection{Organoleptic evaluation of fried} potato chips by using the modified fryer

As shown in Table (2) the sensory evaluation revealed that fried potato chips were more acceptable with the best flavor, crispness and greasiness compared to CDF design samples. Whereas, overall acceptability scores for those samples were ranged from 3 and 4.8 against 3.8 of CDF method. Fried potato chips during the first level of water injection had the highest $(\mathrm{p} \geq 0.05)$ flavor (4.6), crispness (4.5) greasiness (4.6) and the overall acceptability (4.8) compared to fried potato chips during another levels of water injection.

Table (2): Organoleptic evaluation during deep fat frying of potato chips at $170{ }^{\circ} \mathrm{C}$ for $40 \mathrm{hrs}$.

\begin{tabular}{|c|c|c|c|c|c|c|}
\hline \multicolumn{2}{|l|}{$\begin{array}{l}\text { Properties } \\
\text { Treatment }\end{array}$} & Frying time (hrs) & Flavour & Crispness & Greasiness & Overall acceptability \\
\hline \multirow{5}{*}{\multicolumn{2}{|c|}{ Control }} & 8 & 4.3 & 4.0 & 3.6 & 3.8 \\
\hline & & 16 & 4.4 & 4.1 & 3.6 & 3.8 \\
\hline & & 24 & 4.2 & 3.8 & 3.4 & 3.5 \\
\hline & & 32 & 3.4 & 3.3 & 3.2 & 3.0 \\
\hline & & 40 & 3.0 & 3.0 & 3.1 & 3.0 \\
\hline \multirow{5}{*}{\multicolumn{2}{|c|}{ Without water injection }} & 8 & 4.5 & 4.2 & 4.2 & 4.5 \\
\hline & & 16 & 4.5 & 4.4 & 4.0 & 4.4 \\
\hline & & 24 & 4.3 & 4.0 & 3.8 & 4.0 \\
\hline & & 32 & 3.8 & 3.7 & 3.5 & 3.6 \\
\hline & & 40 & 3.5 & 3.5 & 3.3 & 3.4 \\
\hline \multirow{15}{*}{$\begin{array}{l}\text { Injection water } \\
\text { level (ml/batch) } \\
\text { during frying of } \\
\text { potato chips at } \\
170 \mathrm{C}{ }^{\circ} \text { for } 40 \\
\text { hrs. }\end{array}$} & \multirow{5}{*}{0.1} & 8 & 4.5 & 4.2 & 4.6 & 4.8 \\
\hline & & 16 & 4.6 & 4.5 & 4.4 & 4.6 \\
\hline & & 24 & 4.5 & 4.3 & 4.0 & 4.2 \\
\hline & & 32 & 4.0 & 4.0 & 3.8 & 4.0 \\
\hline & & 40 & 3.6 & 4.0 & 3.6 & 4.0 \\
\hline & \multirow{5}{*}{0.2} & 8 & 4.3 & 4.1 & 4.4 & 4.6 \\
\hline & & 16 & 4.4 & 4.4 & 4.3 & 4.2 \\
\hline & & 24 & 4.1 & 4.1 & 4.0 & 3.8 \\
\hline & & 32 & 3.6 & 4.0 & 3.6 & 3.6 \\
\hline & & 40 & 3.2 & 3.8 & 3.4 & 3.4 \\
\hline & \multirow{5}{*}{0.3} & 8 & 4.1 & 3.9 & 4.1 & 4.2 \\
\hline & & 16 & 4.0 & 4.0 & 4.0 & 3.8 \\
\hline & & 24 & 3.8 & 3.8 & 3.8 & 3.4 \\
\hline & & 32 & 3.4 & 3.6 & 3.4 & 3.2 \\
\hline & & 40 & 3.0 & 3.4 & 3.2 & 3.0 \\
\hline \multicolumn{2}{|l|}{ LSD 5\% } & & 1.01 & 1.05 & 0.5 & 0.7 \\
\hline
\end{tabular}


From the overall acceptability rating, it was concluded that a MDF could be injected water up to $0.2 \mathrm{ml} / 20 \mathrm{~min}$. per 1 liter without affecting their sensory quality. It is interesting to notice that sensory evaluation correlated significantly with the deterioration occur in quality attributes in oil during deep fat frying. Additionally, sensory evaluation data are providing us with the information about the thermal stability for quality properties of fried potato chips and oil frying media. The negative correlation coefficient between overall acceptability and $P$ anisidine values was high $(\mathrm{r}=0.935)$. For the third level of water injection followed by the first level of water injection( $r=$ 0.832 ) and then the second level of water injection $(r=-0.795)$, compared with $\mathrm{CDF}$ design. The linear regression equation for prediction the anisidine values of oil was:

$\mathrm{Y}(p-$ anisidine $)=59.913-11.383 \mathrm{X}$ (overall acceptability) $r=(-0.935)$

Same trend was noticed with the most another sensory attributes throughout the whole experiment period. These findings could be supported by Basuny et al. (2012) and Ahmad et al. (2013). Generally, it is worthy to mention that a linear decrease with a significantly correlation between sensory evaluation and oil deterioration parameters except acid value, the correlation coefficient was very weak., the results suggest that determination of oil deterioration parameters are good marker of sensory evaluation during deep fat frying. These data are in the same line with those reported by El-Nagar (2007). Nevertheless, water spray injection may provide protection to the frying oil by steaming out volatile oxidized substances and free radical, and reducing residual dissolved oxygen. It seems to play a crucial role as physical agent for steaming out the volatile oxidative products were found in vapor inhalation and enhancing their evaporation and condensation by steam blanketing design.

\section{Conclusions}

Results indicate that, water injection can both a accelerate hydrolysis and furnish protection against oxidation. Thereafter, these data suggest that the evaporating water do indeed create a steam blanket above the oil surface. The additional properties role of the evaporating water is due to the steam out and distillation effect that reduces the concentration of dissolved oxygen, and drives out oxidized volatile compounds, and possibly also free radicals generated during the frying process MDF design can be applied as simple method to maintain oil quality during deep fat frying.

\section{References}

AOAC (2005), Official methods of analysis association of official analytical chemists, International $20^{\text {th }}$ Edition, The Association of Official Analytical Chemists, Washington, D.C., USA.

AOCS (1992), Official methods and recommended practices of the American oil chemists Society, $5^{\text {th }}$ Edition , American Oil Chemists' Society Press, Champaign, Illinois, 
USA, pp. 18-90 .

Abd-ElGhany, M .E. (2006), Studies on Egyptian ben (Moringa) seeds as non conventional source of edible oil, Ph.D. Thesis, Faculty of Agriculture, Al-Azhar University, Cairo, Egypt.

Ahmad, D. S., Sugiyarto, L., Solichatun, B. and Susilowati, A. (2013), "Review: Physical, physical chemistries, chemical and sensorial characteristics of the several fruits and vegetable chips produced by low-temperature of vacuum frying machine", Bioscience, Vol. 5 No.2, pp. 86-103.

Andrikopoulos, N. K., Boskou, G., Dedoussis, G. V. and Chiou, A. (2003), "Quality assessmen of frying oils and fats from 63 restaurants in Athens, Greece", Food Service Technology, Vol. 3, pp. 49-59.

Basuny, A. A. M., Shaker, M. A. and Ahmed, A. (2012), "Vacuum frying: An alternative to obtain high quality potato chips and fried oil", Global Advanced Research Journal of Microbiology, Vol. 1 No.2, pp. 1926.

Dana, D., Blumenthal, M. M. and Saguy, I. S. (2003), "The protective role of water injection on oil quality in deep fat frying conditions", European Food Research Technology, Vol. 217, pp. 104-109.

Danopouls, A. A. and Ninni, V. L.
(1972), "Detection of frozen fish deterioration by ultraviolet spectrophotometric method", Journal of Food Science, Vol. 37, pp. 649-654.

Delgado, R. M., Luna-Barcenas, G., Arambula-Villa, G., Azuara, E., Lopez-Perea, P. and Salazar, R. (2014), "Effect of water activity in tortilla and its relationship on acrylamide content after frying", Journal of Food Engineering, Vol. 143, pp. 1-7.

Diamante, L. M., Hellmann, A., Shi, S. and Busch, J. (2015), "Vacuum frying foods, Process and Optimization", International Food Research Journal, Vol. 22 No.1, pp. 15-22.

Dueik, V., Robert, P. and Bouchon, P. (2010), "Vacuum frying reduce oil uptake and improves the quality parameters of carrot crisps", Food Chemistry, Vol. 119, pp.1143-1149.

El-Naggar, E. A. (2007), Effect of different heat treatments on the physical, chemical and biological characteristics of some edible oil, $\mathrm{Ph} . \mathrm{D}$. Thesis, Faculty of Agriculture, Al-Azhar University, Cairo, Egypt.

Fan, L. P., Zhang, M., Xido, G. N., Sun, J. C. and Tao, Q. (2005), "The optimization of vacuum frying to dehydrate carrot chips", International Journal of Food Science and Technology, Vol. 40, pp. 911-919. 
Fujisaki, M., Endo, Y. and Fujimoto, K. (2002), "Retardation of volatile aldehydes formation in the exhaust of frying oil by heating under low oxygen atmospheres", Journal of the American Oil Chemistry' Society, Vol.79 No.9, pp. 909-914.

Garayo, J. and Moreira, R. (2002), "Vacuum frying of potato chips", Journal of Food Engineering, Vol. 55, pp. 181-191.

IUPAC (1987), Standard method for the analysis of oils, fats and derivatives, $7^{\text {th }}$ ed., Wiley-Blackwell, New Jersey, USA.

Keeny, P. G. (1971), "A guide to controlling oxidation in butter creams", Candy and Snack Industry, Vol. 136, pp. 58-63.

Martin, F. L. and Ames, J. M. (2001), "Comparison of flavor compounds of potato chips fried in palmolein and silicone fluid", Journal of the American Oil Chemistry' Society, Vol. 78 No. 8, pp. 863-866.

Nayak, P. K., Dash, U., Rayaguru, K. and Krishnan, K. R. (2015), "Physico-chemical changes during repeated frying of cooked oil: a review", Journal of Food Biochemistry, Vol. 40, pp. 371-390.

Negishi, H., Nishida, M. Y. and Fujimoto, K. (2003), "Effect of a modified deep fat fryer on chemical and physical characteristics of frying oil", Journal of the American Oil
Chemistry' Society, Vol. 80 No.2, pp. 163-166.

Miguel, M. G., Antunes, M. D., Rohaim, A., Figueiredo, A. C., Pedro, L. G. and Barroso, J. G. (2014), "Stability of fried olive and sunflower oils enriched with Thym bracapitata essential oil", Czech Journal Food Science, Vol. 32 No. 1, pp. 102-108.

Ogunmoyela, O. A. B., Jimoh, M. O. and Ogabi, O. N. (2016), "Development and evaluation of a malti-heat source deep fat fryer", African Journal of Food Science and Technology, Vol. 7 No. 3, pp. 51-59.

Pedreschi, F. and Moyano, P. (2005), "Oil uptake and texture development in fried potato slices", Journal of Food Engineering, Vol. 70 No.4, pp. 557-563.

Rimac-Brncic, S., Leas, V., Rade, D. and Simundic, B. (2004), "Decreasing of oil absorption in potato strips during deep fat frying", Journal of Food Engineering, Vol. 64, pp. 237-241.

Saguy, I. S. and Dana, D. (2003), "Integrated approach to deep fat frying: engineering, nutrition, health and consumer aspects", Journal of Food Engineering, Vol. 56, pp. 143152.

Sammak, A. R. (2013), "Changes of cotton seed oil quality used for frying of some food types in Damascus city", Damascus University Journal of Agricultural 
Sciences, Vol. 1 No. 29, pp. 223236.

Seppanen, C. M. and Csallany, A. S. (2002), "Formation of 4hydroxynonenal, a toxic aldehydes in soybean oil at frying temperature", Journal of the American Oil Chemistry' Society, Vol. 79 No. 10, pp. 1033-1038.

Shaker, M. A. (2014), "Air frying a new technique for produce of healthy fried potato strips", Journal of Food and Nutrition Sciences, Vol. 2 No.4, pp. 200-206.

Statistical Graphics Crop. (1998), Stat graphics plus, version 4.0, Manugisticus Inc., USA.

Susinggih, W. Y., Hidayat, N. and Anang, L. (2000), "Determination of frying temperature and vacuum pressure to produce pineapple chips using simple vacuum fryer", Determination of Frying Temperature, Vol. 4 No. 4, pp. 129132.
Suxuan, X. and William, L. K. (2012), "Comparative study of physical and sensory properties of corn chips made by continuous vacuum drying and deep fat frying", LWT-Food Science and Technology, Vol. 48, pp. 96-101.

Takeoka, G. R., Full, G. H. and Dao, L. T. (1997), "Effect of heating on the characteristics and chemical composition of selected frying oils and fats", Journal of Agricultural Food Chemistry, Vol. 45, pp. 32443249.

Tompkins,C., and Perkins, E .G. (1999), "The evaluation of frying oils with the $P$ - anisidine value, Journal of the American Oil Chemistry' Society, Vol. 76 No. 8, pp. 945-947.

Zhang, Q., Saleh, A. S. M., Chen, J. and Shen, Q. (2012), "Chemical alterations taken place during deep fat frying based on certain reaction products: a review", Chemistry and Physics of Lipids, Vol. 165, pp. 662681. 